\title{
POLÍTICA FISCAL, CRECIMIENTO SOSTENIDO Y DESARROLLO ECONÓMICO: LA EXPERIENCIA MEXICANA
}

José Luis Hernández Mota*

(Recibido: Marzo 2012 / Aprobado: Julio 2012 )

\section{Resumen}

El objetivo de este trabajo es mostrar que la política fiscal es una herramienta poderosa tanto para la política de estabilización como para generar políticas de desarrollo económico en economías emergentes como la mexicana, mediante el desarrollo de un modelo generalizado de política fiscal y desarrollo económico. Se destaca el uso potencial de la política fiscal como instrumento de desarrollo a través de la promoción del crecimiento económico, combate a la pobreza y la desigualdad y consolidación democrática dada por la legitimidad fiscal de un sistema impositivo progresivo y transparente.

Palabras clave: política fiscal, desarrollo económico, desigualdad Clasificación JEL: E62, H30, H60, O11

\section{Abstract}

The objective of this work is to show that fiscal policy is a powerful tool for stabilisation policy both as to generate economic development policies

* Profesor-investigador del Departamento de Economía de la Universidad Autónoma Metropolitana, Unidad Azcapotzalco. Correo electrónico: <jlhm@correo.azc.uam.mx>, <jlhernandm@prodigy.net. $m x>$. 
José L. HeRnÁNDEZ

in emerging economies as Mexico, through the development of a model fiscal policy and economic development. Highlights the potential use of fiscal policy as a tool of development through the promotion of economic growth, combat poverty and inequality and democratic consolidation given by the fiscal legitimacy of a progressive and transparent taxation system.

Keywords: fiscal police, economic development, inequality JEL Classification: E62, H30, H60, O11

\section{Introducción}

Dentro de la literatura económica existe el consenso que señala que uno de los determinantes del bienestar económico y de los niveles de ingreso per cápita de una economía es la política fiscal. Sin embargo, se debe considerar que el consenso toma dos vertientes. Un punto de vista respecto a la política fiscal es que ésta frena el crecimiento económico por medio de los efectos distorsionadores de los impuestos y el gasto público ineficaz (Kormendi y Meguirre, 1985; Barro, 1990; Lucas, 1990; Easterly y Rebelo, 1993; Jones, Manuelli y Rossi, 1993; Kneller, Bleaney y Gemmell, 1999; Doménech y García, 2002). El otro punto de vista es que el gobierno, por medio de la política fiscal, juega un papel central en el desarrollo económico mediante la provisión de bienes públicos e infraestructura (Gramlich, 1994; Conrad y Seitz, 1994 y Albala-Bertrand y Mamatzakis, 2001).

Sin embargo, la vinculación entre el desarrollo económico y la política fiscal que la promueva es un tema que sigue pendiente, sobre todo cuando en la mayor parte de las economías, especialmente las emergentes y subdesarrolladas, siguen prevaleciendo bajas tasas promedio de crecimiento y una alta vulnerabilidad a disturbios externos. ${ }^{1}$ Estos factores han contribuido a que en estas economías los problemas del subdesarrollo como los migratorios, de pobreza extrema y de desigualdad del ingreso, continúen vigentes. En este sentido, no ha emergido ni una estrategia de desarrollo ni

1 Aunque en los últimos 30 años los países emergentes han vivido fases contrastantes: por un lado, un rápido y sostenido crecimiento económico experimentado por los países del sudeste asiático durante la década de 1970 y 1980 y de China en los últimos 20 años; mientras, por otro lado, efectos reales negativos provocados por la crisis de la deuda de los ochenta y por las crisis financieras de los noventa, y en la primera década del presente siglo en los países emergentes de América Latina, Asia y Europa, así como por la reciente crisis financiera de 2008 en las principales economías industrializadas. 
enfoque fiscal que le sirva de apoyo, de manera tal que se logren procesos de industrialización, competitividad y sistemas fiscales democráticos que ayuden a eliminar las expresiones del subdesarrollo. Actualmente, la estrategia dominante para el desarrollo ha sido la de utilizar la política fiscal para dar continuidad a la estabilidad de precios y de paridades cambiarias.

En términos fiscales, la columna vertebral de los sistemas impositivos es virtualmente el mismo puesto que en la mayor parte de las economías los ingresos fiscales descansan en los causantes cautivos y en ingresos no tributarios. Esto significa que, estructuralmente hablando, los sistemas fiscales son inflexibles y las reformas fiscales sólo responden a factores coyunturales. En cambio, un sistema impositivo que respete los principios de suficiencia y elasticidad ${ }^{2}$ puede servir a una política de desarrollo que genere procesos dinámicos de industrialización, competitividad e ingresos. Aunque ello implicaría la demanda de acumulación de capital, cambio técnico, adopción de apropiadas decisiones en materia de infraestructura y un constante mejoramiento del capital humano. El sistema impositivo, lo que menos debe hacer es entorpecer los incentivos hacia el trabajo, la innovación, la inversión productiva y los alicientes personales que sirven de entorno favorable a los negocios. ${ }^{3}$

Por su parte, en materia de gasto público los atributos de utilidad, productividad y rendimiento económico y social deberían orientar las decisiones, junto con eficientes criterios de auditoría para conjurar las desviaciones de fondos públicos que incentivan pretextos para evadir y

2 Esto es, que permita fiananciar satisfactoriamente las erogaciones y conlleve amortiguadores contracíclicos para no agudizar las tendencias subyacentes en el sistema político-económico. Para ello, los impuestos que recaen sobre ventas y sobre los ingresos personales, como el impuesto al valor agregado (IVA) y el impuesto sobre la renta (ISR) en el sistema tributario mexicano, se deben ajustar a los mencionados requerimientos y devengar siempre que existan beneficios y no satisfacerse aunque la situación de los contribuyentes sea ruinosa. Esta condición apuntala una estrategia de desarrollo que no sea indiferente a pautas de equidad social.

3 Por ejemplo, para estimular la acumulación de capital no parece razonable gravar por igual a quienes reinvierten todo o parte de los beneficios que a quienes los distraen en otras cosas. Reducir la contribución de los primeros no sólo mejora el desempeño de la economía, la demanda de empleo y eventualmente la diversificación del Producto Interno Bruto (PIB), sino también la equidad en el sistema tributario. La inclusión de ganancias extraordinarias por ventas de activos o financieras, bajo ciertas condiciones que no desestimulen el ahorro, deben estar presentes. Por ejemplo, en el sistema impositivo mexicano, mientras el IVA subsista, lo menos que debería hacerse es eximir a la mayor cantidad de productos sensibles que integran la canasta familiar básica. Como factor de compensación deberían alcanzarse fuertemente los gastos reveladores de potencia económica como combustibles, juegos de azar, etc., lo cual demostraría que el poder político distribuye con criterio de justicia la carga tributaria sobre la sociedad. 
José L. HERNÁNDEZ

se traducen en crecientes aprietos a los desalentados contribuyentes cuyo desempeño suele ser fiscalmente más transparente. Para acometer la difícil tarea dirigida a formular un programa fiscal orientado a apuntalar y no a obstaculizar el desarrollo pendiente, cualquier intento de reforma fiscal debería estar necesariamente subordinado a objetivos macroeconómicos trascendentes. En este sentido, los impuestos y gastos públicos bien establecidos son herramientas para alcanzarlos. Si la política fiscal no contempla este aspecto pierde su vinculación con el desarrollo.

Bajo esta perspectiva, es pertinente preguntarse: ¿el desempeño deficiente de la economía y su vulnerabilidad frente a disturbios externos, es producto de la política fiscal adoptada?, ¿cómo ultilizar la política fiscal para estimular el crecimiento?, ¿es la política fiscal un instrumento eficaz para resolver los problemas del desarrollo?

La explicación de estas interrogantes permite mostrar cómo las decisiones de política fiscal afectan los intereses tanto de individuos como de grupos, de comunidades y países, por lo tanto, el enfoque analítico de las decisiones fiscales contribuyen a resaltar el hecho de que estas decisiones son cruciales pues determinan el corto y largo plazo de una economía.

Nuestro análisis examina en la siguiente sección cómo es tratada la relación entre la política fiscal y la política de desarrollo, considerando, en primera instancia, un marco conceptual básico para establecer dicha relación. En la sección tres se propone un modelo que sirva de fundamento para los principales argumentos y resultados teóricos del análisis de los efectos de la política fiscal en el proceso de desarrollo económico. En la cuarta sección se presenta una panorámica de la evidencia macroeconómica para la economía mexicana con el fin de poner a prueba la consideración de si la política fiscal es un instrumento adecuado para los objetivos de la política de desarrollo. Por último, se presentan las conclusiones.

\section{Conceptos básicos de política fiscal}

Es un hecho aceptado que la acción pública puede clasificarse en cuatro categorías (Musgrave y Musgrave, 1984): i) acciones de regulación respecto al comportamiento de los agentes económicos, ii) acciones de producción de bienes y servicios, iii) acciones de acumulación, y iv) acciones de financiamiento. Estas acciones se expresan por medio de la política económica la cual, en esencia, tiene dos componentes básicos: la política fiscal y la 
política monetaria, donde esta última tiene la finalidad de regular la oferta monetaria a las necesidades de la economía para garantizar la estabilidad de corto plazo y satisfacer los requerimientos del crecimiento a mediano y largo plazo. Por su parte, la política fiscal se clasifica en política presupuestaria y política tributaria. La primera está relacionada con el nivel y estructura de los gastos públicos y con el nivel de los ingresos públicos, sean tributarios, no tributarios o producto de endeudamiento. Mientras, la política tributaria trata de la distribución de la carga fiscal y de los efectos impositivos sobre el crecimiento económico. Por tanto, la especificación de dichas políticas conforma una determinada política fiscal.

Ahora bien, la política fiscal en cuanto a instrumento de manejo de los ingresos y gastos públicos, además de cumplir con las funciones asignativas y de estabilización, puede tener también las funciones de promoción de desarrollo y de distribución, sobre todo en los países en desarrollo (Nurske, 1953). La función de asignación se refiere a la asignación de recursos para la producción de bienes que satisfagan las necesidades sociales, los cuales, por su naturaleza, no pueden ser provistos eficientemente por el mercado (Samuelson, 1954). Este tipo de bienes "públicos" son aquellos cuyo consumo es no excluible y no rival. Es decir, que el beneficio que obtiene una persona al consumirlos no reduce el beneficio derivado por los demás consumidores. En consecuencia, resulta ineficiente aplicar el principio de exclusión (cobrar un precio), aun cuando sea posible hacerlo. Esto es, como la asignación óptima de recursos se logra cuando el precio del bien o servicio coincide con su costo marginal, entonces dado que el costo de satisfacer un consumidor adicional (costo marginal) es cero, el precio debe ser cero, independientemente de que el costo medio sea distinto de cero. Así, el problema de la política fiscal respecto de la provisión de bienes públicos consiste en determinar la cantidad del bien o servicio a proveer y la forma en que se cubrirá su costo.

Sin embargo, es necesario distinguir entre provisión y producción de bienes públicos. En general los bienes privados tienen ese carácter en tanto que son vendidos a los consumidores privados y son producidos por empresas tanto privadas como públicas; en cambio, los bienes públicos también pueden ser producidos por empresas privadas o públicas, pero su distinción con los bienes privados es que son financiados mediante el presupuesto público y puestos a disposición de los consumidores libres de un pago directo. Por tanto, la decisión de asignar recursos a la producción de bienes públicos o privados es diferente respecto a si la producción será hecha por empresas 
privadas o públicas; por lo cual, el problema central consiste en determinar el volumen y estructura de bienes públicos que satisfacen las necesidades sociales, evitando el problema de la congestión (Bergstrom et al., 1986).

Paralela a la función de asignación se encuentra la función de promoción del desarrollo de la política fiscal, referida más concretamente a los efectos de ésta sobre el crecimiento económico, donde éste se concibe dentro de la literatura económica como función de la expansión del stock de factores productivos de la economía y del incremento de su productividad. Por ejemplo, dentro de los países emergentes, los elementos críticos para el crecimiento son la formación de capital y la productividad de los factores (Nurske, 1953). Por tanto, un objetivo de la política fiscal es incidir sobre ellos.

La contribución del sector público a la formación de capital ocurre de manera directa por medio de la inversión pública y del ahorro interno. ${ }^{4} \mathrm{El}$ mecanismo es el siguiente: las decisiones financieras del sector público (déficit o superávit público) y los incentivos tributarios al sector privado determinan en gran medida la tasa de inversión, por lo que ello afecta al ahorro interno e incide sobre la expansión del stock de capital, el cual, además de ser el medio de incorporación del avance tecnológico, incide sobre el aumento de la productividad de éste y otros factores. Lo mismo aplica también si el gasto público se dirige a la formación de capital humano, sobre todo cuando se plantean un conjunto de medidas destinadas principalmente a mejorar la eficiencia del sector privado como son los efectos inductores del sistema tributario y las acciones directas como: provisión de infraestructura, servicios de apoyos a los productores agrícolas e industriales, fomento tecnológico, etcétera.

Por su parte, la política fiscal también tiene una importante contribución al desarrollo por medio de su capacidad de alterar la distribución del ingreso a través de impuestos, provisión de bienes públicos, transferencias personales u otras medidas de política social. Si la distribución del ingreso en un momento dado es producto de un patrón distributivo particular, mismo que afecta la distribución general, entonces, aun si el mercado funcionara perfectamente, se generaría una distribución del ingreso que no necesariamente coincidiría con lo que una sociedad pudiere considerar justa. La razón se encuentra en

4 Entre los estudios para la economía mexicana destacan los de Feltenstein y Ha (1999), Ramírez (2007), Fonseca (2009), Hernández (2010), los cuales señalan la importancia del gasto público en la formación del capital y el ahorro interno como fuente del crecimiento económico. 
que el proceso distributivo requiere ser abordado con un criterio más amplio que el económico en el que se incluyan consideraciones sociales y políticas, entre otras, debido a que los factores que influyen en la distribución del ingreso van desde las capacidades de los individuos para obtener ingresos, que dependen de las capacidades productivas y de la estructura de propiedad de los medios de producción, hasta la acción pública de la tributación, el gasto público y los efectos de las políticas sociales y económicas establecidas, pasando por la acción propia del mercado para determinar tanto los precios relativos de los factores productivos como su nivel de empleo en los distintos sectores de la actividad económica.

Sin embargo, el campo más reconocido de la acción de la política fiscal es cuando funge como herramienta para realizar la función estabilizadora de la política económica. En este sentido, existe un consenso en donde se señala que la política fiscal es necesaria para la estabilización, debido a que el nivel de empleo requerido y la estabilidad de precios no resultan de forma automática en una economía de mercado, sino que su consecución requiere de la orientación de la política pública previamente establecida, generadora de capacidades productivas adicionales en la economía (Lucas, 1990; Barro, 1990; Easterly y Rebelo, 1993 y, Turnovsky, 2000). Esta concepción de la acción de la política fiscal está en el centro de los modelos de crecimiento endógeno y supera la visión tradicional que se tenía de ella, al considerarse que sus efectos también ocurren en el lado de la oferta y no sólo en la demanda agregada, pues el nivel de empleo y precios dependen tanto del nivel de esta última como de la capacidad productiva de la economía. ${ }^{5}$

Ahora bien, en la consecución de los objetivos de desarrollo económico de la política fiscal, ésta se expresa por medio del flujo de ingresos y gastos del sector público que interfiere en el funcionamiento del sistema productivo de diversas maneras. Desde el punto de vista de los ingresos, éstos provienen de tres fuentes principales: ingresos tributarios o impuestos, corrientes o no tributarios (por venta de bienes y servicios principalmente) y endeudamiento. Los ingresos tributarios y corrientes son sustracciones al sector privado sin

5 Dentro de la visión tradicional de la política fiscal se considera que si el nivel de la demanda agregada está en función de las decisiones de gasto de los agentes económicos, mismas que dependen de factores diversos como el ingreso pasado y presente, la riqueza, la disponibilidad de crédito, las expectativas, etc., entonces, en un momento dado, la demanda puede diferir del gasto requerido para garantizar el pleno empleo de los factores productivos. En esta circunstancia, es necesaria la implementación de políticas expansivas o restrictivas de la demanda a fin de mantener la estabilidad, sin olvidar que para lograr la eficacia requerida debe de haber una adecuada coordinación con la política monetaria. 
contrapartida; es decir, que no generan obligaciones para con quien los paga. En cambio, el endeudamiento genera una obligación de repago futuro y de pago de intereses en el periodo intermedio.

De las fuentes de los ingresos públicos, la tributación es el instrumento generalmente aceptado para llevar a cabo la acción del Estado sobre el proceso económico, caracterizada por un conjunto de funciones básicas que debe cumplir la política tributaria en la implementación de distintas estrategias de desarrollo. En este sentido, el consenso señala que la política impositiva es un instrumento que tiene la capacidad para influir en el comportamiento de los agentes en el sistema económico y, como tal, constituye uno de los instrumentos básicos de política económica para el crecimiento económico (Jones, Manuelli y Rossi, 1993 y Doménech y García, 2002).

No obstante lo anterior, también hay que tener presente que no todos los objetivos de una política de desarrollo (sobre todo cuando no sólo implica la consecución de crecimiento económico sino que abarca objetivos de extinción de pobreza o desigualdad, por ejemplo), son susceptibles de consecución por medio de instrumentos tributarios. Aunque el impuesto es una fuente de ingresos públicos, también es un instrumento capaz de afectar (favorable o desfavorablemente) el comportamiento de los agentes económicos. Por consecuencia, la política tributaria no es un instrumento apto para alterar una determinada distribución de la propiedad del stock de factores productivos existentes en un momento determinado dentro de una economía dada. Para ello se requieren medidas específicas y directas: reforma agraria, industrial, financiera, etc. Aun cuando la presión tributaria puede forzar la transferencia de patrimonio entre personas, no puede promover su redistribución entre grupos sociales en forma masiva. La razón está en que la tributación opera sobre los flujos de la economía y, como tal, su reordenación puede afectar, sólo de manera marginal, la distribución futura de la propiedad de los factores productivos. ${ }^{6}$

6 Debe tenerse en cuenta que, si bien los impuestos influyen sobre la orientación de los flujos reales y financieros de la economía mediante dos mecanismos distintos y complementarios entre sí, como son las transferencias al sector público de los ingresos generados por el sistema económico (mismos que retornan al sistema en la forma de gasto corriente o de capital) y la reasignación de recursos dentro del sector privado inducida por la disminución del ingreso disponible de empresas y personas (efecto ingreso), así como por la alteración de la estructura de precios relativos bienes y factores (efecto precio); ambos mecanismos afectan la asignación privada de recursos al alterar el nivel y estructura de la demanda (final e intermedia) en función de los coeficientes de elasticidad precio e ingreso de la demanda. 
Por otra parte, aunque a mediados del siglo xx había la convicción relativa a que una política de endeudamiento era necesaria para la consecución de procesos de industrialización y desarrollo (Rosenstein-Rodan, 1943 y Nurske, 1953), las consecuencias económicas obtenidas por las economías latinoamericanas en la década de 1980 que siguieron una política de endeudamiento, basadas en la generación de déficit fiscales, llevó al consenso teórico de que dicho instrumento no era económicamente óptimo. Por ejemplo, Baldacci et al. (2003) encuentran que para una muestra de 39 países durante el periodo 1990-2000, el objetivo de crecimiento puede lograrse con una política de desendeudamiento (o no endeudamiento), de tal manera que se tengan superávits fiscales en lugar de déficits. Así, señalan que, conforme sus resultados obtenidos, el crecimiento aumenta en $0.25 \%$ conforme se logran superávits presupuestales de $1 \%$ del PIB, mientras los aumentos del déficit lo deprimen en proporción similar, concluyendo que el ajuste fiscal no es un obstáculo al crecimiento como comúnmente se piensa.

Asimismo, la política fiscal también cuenta con el instrumento del gasto público, el cual está directamente asociado con sus funciones asignadas, entre las que destaca la consecución de objetivos de desarrollo. No obstante, hay que destacar que el papel del sector público en el sistema económico y, por consecuencia, la magnitud del gasto público como proporción del producto total, constituye un marco determinado por factores históricos, sociales y políticos fuera del alcance de las políticas económicas de tipo instrumental.

Esto implica que los factores mencionados constituyen los condicionamientos globales de la actuación del sector público, derivados de los conflictivos intereses individuales y colectivos del sistema, y son los que determinan las oscilaciones y estructura del nivel de gasto. Lo que significa que la preservación del nivel de ingreso y empleo, como objetivo de política económica, queda supeditada a los condicionantes pues, al tener compromisos entre múltiples objetivos el logro de uno implica el sacrificio de otro. Así, la concepción del gasto público tiene que ser vista primero como un dato históricamente determinado por las necesidades sociales y los compromisos políticos, antes que un proceso de elección económica. Esto conlleva a superar la visión inicial provista por Samuelson (1954) respecto a la determinación del nivel óptimo del gasto.

Bajo estas consideraciones, el gasto público, en términos generales, se divide principalmente en dos categorías: gasto corriente y gasto de capital. El primero lo constituye el pago de remuneraciones, las compras del sector público y las transferencias al sector privado. La compra de bienes y servicios 
José L. HERNÁNDEZ

más el pago de remuneraciones constituye el costo de los servicios públicos, mismos que corresponden a los gastos de la administración general del Estado y a la provisión de bienes públicos. Las transferencias, por su parte, están asociadas directamente al objetivo redistributivo. Mientras el gasto de capital es la adición al patrimonio de la economía por medio de obra pública o adquisición de bienes inmobiliarios, los cuales incrementan la infraestructura física disponible.

\section{Política fiscal y objetivos de desarrollo: un modelo teórico ${ }^{7}$}

Un postulado macroeconómico comúnmente aceptado es que la política fiscal puede ayudar a estimular la demanda agregada y reactivar una economía estancada. La razón es que el tamaño del sector público, las distintas funciones del gasto público y la estructura fiscal a través de la cual se financia el sector público, influyen en las decisiones económicas y en la actuación de los agentes privados. Por tanto, los efectos de la política fiscal sobre el crecimiento económico a largo plazo han recibido una especial atención en la literatura especializada, en particular desde mediados de los años ochenta con el florecimiento de nuevas teorías de crecimiento endógeno.

Sin embargo, el consenso teórico respecto a la actuación de la política fiscal muestra que si los niveles de deuda pública son altos para una economía en particular, entonces no es recomendable aplicar una política expansiva para tratar de sacar a una economía de una recesión. El argumento es el siguiente: un incremento del déficit público puede dar lugar a un descenso de la inversión y el consumo privados (por medio del conocido efecto crowding$o u t$ ), anulando el efecto de un aumento del gasto público o de una reducción de impuestos en la demanda agregada.

Aunque, paradójicamente, una reducción del déficit puede acelerar el crecimiento económico cuando la deuda pública es alta e insostenible, pues la reducción del financiamiento público suele presionar a la baja las tasas de interés, alentando la inversión y elevando el valor de los activos (efecto riqueza). Esto puede incentivar el consumo y la inversión privados (demanda agregada). De aquí se deduce la recomendación ortodoxa acerca de que los ajustes fiscales basados principalmente en el recorte de las subvenciones, las

Esta sección y la siguiente están basadas en Hernández (2011), capítulos 4 y 5. 
transferencias (las pensiones, por ejemplo) y las remuneraciones del sector público, suelen ser más duraderos y pueden tener efectos expansivos sobre la economía por medio de la reducción del déficit público. En cambio, los que se logran elevando los impuestos suelen ser contractivos e insostenibles.

Considerando lo anterior y en la perspectiva del análisis de la teoría del crecimiento endógeno, la política fiscal tiene repercusiones sobre la actividad y los resultados económicos en general (Turnovsky, 2000). Aunque esta característica ya la había desarrollado Rosenstein-Rodan (1943) para economías en desarrollo donde la condicionante era que si el instrumento del gasto público se realizaba correctamente, ello podría acelerar el desarrollo. Pero, si su aplicación se daba de manera incorrecta, el resultado es que se provocarían externalidades negativas capaces de provocar el estancamiento o la desintegración económica y social.

Sin embargo, en términos del análisis del crecimiento neoclásico, basado en la ecuación fundamental del modelo de Solow (1956), sólo la normativa y las instituciones públicas eficientes afectan al crecimiento económico. La influencia de estos factores se da sobre la eficiencia con la que se combinan los insumos productivos y sobre las decisiones de capitalización del sector privado. En consecuencia, considerando la siguiente función de producción

$$
Y=A K^{\alpha} L^{1-\alpha}
$$

que expresa la producción total de bienes y servicios, donde $A$ es un índice de eficiencia técnica de la economía (o estado tecnológico), $K$ el stock de capital, $L$ el factor trabajo y $\alpha$ una constante de productividad con valores entre cero y uno. Si el factor trabajo crece a una tasa $n$ y el capital se deprecia a. una tasa $\delta$, entonces el stock de capital crece por unidad de tiempo a la tasa $K=s Y-\delta K$, donde $s$ es la tasa de ahorro de la economía. Si expresamos las relaciones anotadas en términos por trabajador, se tiene

$$
y=A k^{\alpha}
$$

El crecimiento dependerá entonces de la evolución del grado de eficiencia técnica de la economía y del cambio en la relación capital-trabajo, dada por la ecuación fundamental de Solow:

$$
\dot{k}=s A k^{\alpha}-(n+\delta) k
$$




\section{José L. HERnÁNDEZ}

De esta relación, se obtiene la conclusión de que el crecimiento económico tiene causas exógenas y, por tanto, no hay política pública que pueda incidir sobre él, pues si consideramos que en estado estacionario se tiene que

$$
\dot{k}=0 \Rightarrow s y=(n+\delta) k
$$

Esto significa que dada una tasa fija de ahorro, la producción por trabajador está determinada por la tasa de inversión en insumos privados como capital físico y habilidades, por la tasa de crecimiento de la fuerza laboral y por la productividad de los insumos. Por tanto, prevalece una situación donde todas las variables reales crecen a la misma tasa y la relación capital-trabajo es constante, de forma que

$$
k^{*}=\left(\frac{s A}{n+\delta}\right)^{\frac{1}{1-\alpha}} \quad y^{*}=A\left(k^{*}\right)^{\alpha}=A^{\frac{1}{1-\alpha}}\left(\frac{s}{n+\delta}\right)^{\frac{\alpha}{1-\alpha}}
$$

aproximando en torno al estado estacionario:

$$
\begin{gathered}
\frac{\Delta y_{t}}{y_{0}} \approx\left(1-e^{-\beta t}\right)\left(\log y^{*}-\log y_{0}\right) \\
\operatorname{con} \beta=(1-\alpha)(n+\delta)
\end{gathered}
$$

Donde $\beta$ es la velocidad de convergencia al estado estacionario por lo que, la tasa de crecimiento de la economía entre el instante $t$ y el inicial 0 es proporcional a la distancia entre la situación de partida, $\log y_{0}$, y la situación convergente, $\log y^{*}$, relacionando el corto, medio y largo plazo.

En este caso, si la política fiscal utiliza el instrumento gasto público éste puede influir sobre el nivel del producto por trabajador a largo plazo, y lo haría a través del parámetro de eficiencia productiva, $A$, y sobre la tasa de ahorro, s. Ello implica que la política de gasto sí puede afectar el ritmo de crecimiento durante la transición al estado estacionario, pudiendo cambiar las condiciones estructurales dadas por la relación capital-trabajo, 
lo cual va en sentido contrario a lo establecido por el modelo canónico de crecimiento neoclásico. ${ }^{8}$

Entonces, aun suponiendo que la relación tecnológica (función de producción), establecida en términos de capital físico y humano, presentase rendimientos constantes, la eficiencia en la acumulación de capital humano y sus externalidades positivas aumentarían la tasa de crecimiento estacionaria, de acuerdo con la nueva teoría de crecimiento (Turnvosky, 2000).

Adicionalmente, si suponemos también que existe o que es posible una variación en los costos para establecer negocios y en la capacidad de los inversionistas para obtener rendimientos de su inversión, entonces, se puede formular la hipótesis de que es posible y deseable generar un cambio estructural a través de reformas institucionales y/o de políticas públicas. Estas reformas y políticas, para hacer efectivo el cambio estructural, deberán proporcionar tanto las instituciones como la infraestructura que minimicen los costos privados y sociales para el establecimiento y operación de unidades de producción que puedan maximizar los rendimientos esperados $y$, en consecuencia, estimular así a la inversión.

En este sentido, para implementar las reformas o políticas que estimulen la inversión, es necesario tener o generar un gasto público productivo en la producción de servicios públicos que genere capacidades burocráticas "antidemora". Esto permite evitar los "costos hundidos" provocados por la corrupción, sobornos o robos que obliguen la cancelación de los proyectos productivos. Ésta es una condición indispensable que necesita una economía para tener un sector donde se gesten las ideas para el establecimiento de negocios y, por tanto, para mejorar las expectativas de inversión que, en último caso, la impulsen. Dicha capacidad de transformación del gasto público ${ }^{9}$ proporciona un ambiente estructural dinámico, donde el desarrollo inducido de las capacidades productivas, producto del estímulo a la inversión y no al ahorro y la expansión del talento, es una condición necesaria para una economía donde prive la escasez de recursos (insuficiente ahorro). El cumplir con esta condición, puede hacer que los procesos productivos de

8 El supuesto común en los modelos de crecimiento neoclásico es que las tasas de inversión y el tiempo individual a la acumulación de habilidades son proporcionados exógenamente, independientemente de lo que se invierta. Aunque normalmente se acepte que economías que invierten más y dediquen más tiempo al incremento de habilidades son más avanzadas respecto a las que no lo hacen en la misma proporción, sin embargo, no se explica el porqué es así, pues no se hace endógena a la inversión.

$9 \quad$ Esto es, pasar de ser un simple gasto en sueldos y salarios para mantener el nivel de empleo público a un gasto en sueldos y salarios para generar servicios públicos con objetivos productivos definidos. 
José L. HeRnÁNDEZ

la economía aprovechen la inversión productivamente, generando mayores recursos. Esto significa invertir el proceso ahorro-inversión por el de inversión-ahorro.

Otra alternativa de política pública para generar procesos productivos, ha sido desarrollada por Gramlich (1994), Felstenstein y Ha (1999), Fisher y Turnovsky (1998), y Hernández (2010), donde se enfatiza la ampliación y mejoramiento de la infraestructura física y social (o capital público), provista por el gasto público productivo cuyo fin es aminorar los costos derivados de la insuficiente o mala calidad de la infraestructura. Por tanto, la infraestructura de una economía tiene potencialmente una gran influencia sobre la inversión.

Esto significa que la difusión de instituciones e infraestructuras que fomentan la capacidad productiva de la inversión física, favorecen el desempeño económico y fomentan la riqueza. Asimismo, éstas determinan el grado hasta el cual los individuos están dispuestos a realizar las inversiones productivas de largo plazo en capital, habilidades y tecnología asociadas al crecimiento sostenido de largo plazo. En este sentido, ¿Es posible que la infraestructura en algunas economías sea mejor que en otras? ¿Por qué? La respuesta inmediata es que sí. Aunque no hay que olvidar que la burocracia, al querer maximizar su propia utilidad, frena el desarrollo económico por la generación de políticas e instituciones públicas que no fomentan una infraestructura que proporcione un ambiente que favorezca el incremento de la inversión productiva y la productividad que favorezca la generación de riqueza.

Por lo anterior, queda claro que es necesario construir una estructura institucional que favorezca la producción, la cual no es contraria a la imposición fiscal o regulatoria. Simplemente hay que señalar que los impuestos son necesarios para que el sector público pueda proporcionar los bienes y servicios relacionados con la producción y que contribuyan a la disminución de los costos. Esto, por otra parte, genera certeza a la inversión y evita los gravámenes fiscales confiscatorios que restan los ingresos o beneficios obtenidos sobre la inversión, reduciendo su rendimiento.

Así, si introducimos una tasa impositiva, $\tau$, proporcional sobre los ingresos en la trayectoria de equilibrio del ingreso por trabajador, dada por (4), tenemos lo siguiente:

$$
y^{*}=A^{\frac{1}{1-\alpha}}\left(\frac{(1-\tau) s}{n+\delta}\right)^{\frac{\alpha}{1-\alpha}}
$$


Aquí, aparentemente la imposición fiscal directa reduce la tasa de crecimiento de la producción por trabajador, pues (5) indica que una sociedad es más rica cuanto mayor sea su preferencia por el ahorro, más productivo su capital y más eficiente su tecnología, pero los impuestos que recaigan sobre la productividad marginal del capital reducirá el ingreso por trabajador a largo plazo. Aunque, Kneller, Bleaney y Gemmell (1999) muestran que ello sólo ocurre cuando los impuestos son distorsionantes, es decir, cuando un incremento impositivo afecta inversamente al ahorro y, por tanto, a la inversión. En consecuencia, de acuerdo con la teoría neoclásica bastaría cambiar la imposición fiscal directa por la indirecta para estimular el crecimiento económico, pues no se afectaría al ahorro sino al consumo o a los ingresos no impositivos.

Sin embargo, si consideramos la forma de gastar la recaudación fiscal por parte del sector público, entonces los efectos sobre el crecimiento serán distintos. Si la recaudación fiscal directa se gasta en inversión pública, los efectos sobre el crecimiento dependerán de la naturaleza de ésta. Si se gasta en bienes de inversión sustitutivos del capital privado, el gasto público expulsará a la inversión privada sin más efectos sobre el crecimiento que los indirectos (negativos) asociados a los impuestos que financian la inversión. Éste es el conocido efecto desplazamiento. Por otra parte, si el sector público provee bienes de capital (o infraestructuras) que pone a disposición de los agentes privados, el gasto público puede acelerar, en principio, el crecimiento y aumentar el ingreso per cápita a largo plazo. Esta situación se muestra si consideramos una función de producción complementaria entre el capital público y privado la cual puede ser completa, como en Hernández (2009) o parcial como en Barro (1990)..$^{10}$

De manera general, podemos ilustrarla como $y=A k^{\alpha} g^{\beta}$, donde $g$ es capital público por trabajador producto de los flujos de gasto público destinado a su provisión en la economía, $\alpha$ y $\beta$ son las productividades del capital privado y del capital público por trabajador, las cuales pueden generar rendimientos decrecientes, constantes o crecientes. Suponiendo que el capital público es financiado totalmente con los impuestos directos, la producción por trabajador a largo plazo es

10 Las diferencias entre una y otra es que mientras en la primera los rendimientos a escala de la función de producción son crecientes, en la segunda se suponen constantes. Asimismo, en Hernández se contemplan tanto los gastos en inversión pública que contribuyen a la formación del capital agregado como los servicios públicos que incrementan la productividad de los individuos por mejoras en su bienestar, en Barro se contemplan por separado. 
José L. HernándeZ

$$
y^{*}=A^{\frac{1}{1-\alpha-\beta} \frac{\beta}{\tau 1-\alpha-\beta}}\left(\frac{(1-\tau) s}{n+\delta}\right)^{\frac{\alpha}{1-\alpha-\beta}}
$$

así, si la productividad del capital público $\beta$ es alta y éste es utilizado intensivamente por los agentes privados en el proceso productivo, aun cuando produzca una depreciación acelerada, la inversión pública será favorable al crecimiento económico.

Sin embargo, si se produce una congestión del capital público, los efectos positivos serán compensados por los negativos provocados por la recaudación fiscal necesaria para financiarlo. Por tanto, se tiene que procurar una provisión eficientemente productiva de capital público que evite, por un lado, su congestión debido a una asignación errónea y, por el otro, su desperdicio que haga que su productividad disminuya.

Asimismo, de (6) se deduce que la relación inversión pública-PIB que maximiza el crecimiento del producto (ingreso) por trabajador a largo plazo es $\frac{\beta}{\alpha+\beta}$. Esto significa que la inversión pública será productiva cuando el coeficiente sea positivo y será improductiva cuando sea menor o nulo, excepto cuando el nivel de la inversión sea superior o igual al que maximiza el ingreso por trabajador a largo plazo.

Ahora bien, si el gasto del sector público se destina al consumo (consumo público) los efectos podrían ser positivos o negativos dependiendo de la producción de los servicios que genere. Si los servicios producidos y provistos aumentan directamente el bienestar de los individuos, el consumo público reduce el crecimiento, produciendo un subóptimo en términos de éste y un máximo en términos de bienestar social. Si además la producción de servicios es ineficiente, por un problema típico del principal-agente, por ejemplo, el efecto negativo se potencia (Easterly y Rebelo, 1993).

Si parte de la provisión de servicios son directamente utilizados para aumentar el stock de capital humano y son producidos eficientemente, o indirectamente ayudan a incrementar la inversión privada mediante el mejoramiento de la eficiencia productiva de la economía, los impactos del gasto público sobre el crecimiento de largo plazo también serán positivos. Sin embargo, la productividad de los servicios públicos es inversamente proporcional al tamaño del sector público, por lo cual un sector público relativamente grande e ineficiente requerirá una mayor presión fiscal para 
su operación, pero ello conducirá a generar impuestos distorsionantes que provocan efectos negativos sobre el crecimiento.

Respecto al gasto público en transferencias, la posición tradicional señala un nexo negativo entre la redistribución, vía transferencias, y el crecimiento económico. El argumento central es que, por un lado, la redistribución disminuye la tasa de ahorro agregada debido a que los individuos de ingresos bajos tienen una mayor propensión a consumir y, por el otro, los programas sociales distorsionan las decisiones de participación laboral mediante incentivos al ocio. Asimismo, la financiación de las transferencias, vía impuestos, reduce el ingreso disponible para la inversión pues se considera que los recursos empleados en las transferencias elevan el costo de oportunidad en términos del ingreso de largo plazo, ya que se retraen de actividades productivas. Estos factores pueden deducirse de la ecuación (5) donde, al introducirse un impuesto directo en la economía, la productividad se ve afectada reduciendo la tasa de crecimiento. El efecto se recrudece si la recaudación fiscal se desperdicia, se transfiere o se compensa con otras reducciones impositivas.

Pese a los descrito arriba, a la luz de la nueva literatura sobre el crecimiento económico se ha redescubierto que determinadas políticas redistributivas dirigidas a los segmentos más pobres podrían aumentar la productividad y generar un beneficio social positivo. Por ejemplo, García Peñaloza (2003) describe una serie de modelos de crecimiento endógeno que destacan la importancia de los factores institucionales y predicen que una economía tenderá a crecer menos cuando más escaso capital posean los individuos. Así, la redistribución sólo se justifica si se alcanzan tasas de crecimiento eficientes por medio de impuestos o reasignaciones de gasto, asociadas con el desarrollo del capital humano que dependa de la capacidad (talento) y no del ingreso.

Este planteamiento implica que las transferencias pueden aumentar la eficiencia productiva, mediante la corrección de las externalidades provocadas por la distribución del ingreso. Éstas se manifiestan en inversiones subóptimas de recursos en capital humano, que se traduce en un menor crecimiento económico. Esto significa, entonces que una mayor desigualdad distributiva reduce el crecimiento. Por tanto, el sector público puede mejorar la distribución del ingreso, aunque los efectos dependerán del impacto de las transferencias y de los impuestos necesarios para su financiación. Considerando las transferencias en (6) se deduce que el producto por trabajador a largo plazo es: 
José L. HeRnÁNDEZ

$$
y^{*}=A^{\frac{1}{1-\alpha}} h^{\frac{\beta}{1-\alpha}}\left(\frac{(1-\tau) s}{n+\delta}\right)^{\frac{\alpha}{1-\alpha}}
$$

donde $h$ es una medida de capital humano por trabajador y $\tau$ continúa siendo la presión fiscal ya descrita con anterioridad. La desigualdad afecta entonces directamente al parámetro de eficiencia $A\left(\right.$ donde A crece a la tasa $\left.e^{\epsilon_{0}+\epsilon_{1^{d}}}\right)$, en el sentido de que, dentro de una economía, una mayor desigualdad provoca una ineficiencia productiva debido a la diferencia de ingresos que imposibilita el desarrollo pleno de la capacidad productiva de los estratos más bajos de ingresos.

Si $d$ es un indicador de igualdad en la distribución del ingreso, entonces se tiene que

$$
d=d\left(\frac{g}{y}, \eta\right)
$$

en este caso, $g$ representa el gasto social o en transferencias y $\eta$ es un vector de otros determinantes de desigualdad. Si el sector público decidiera incrementar permanentemente los impuestos para destinar los recursos recaudados al gasto social, entonces tendríamos que en el largo plazo sucede que

$$
\frac{d \log y^{*}}{d \tau}=\frac{1}{(1-\alpha)(1-\tau)}\left[\epsilon_{1}(1-\tau) \frac{\partial d}{\partial\left(\frac{g}{y}\right)}-\alpha\right]
$$

Lo cual significa que en una economía donde el capital no sea tan productivo como pudiera serlo, la política redistributiva es beneficiosa para el crecimiento, pues el incremento del coeficiente de la igualdad del ingreso, dada por $\epsilon_{1}$, es más productiva mientras más eficaz sea el gasto social, o las transferencias, en la disminución de la desigualdad $\left(\frac{\partial d}{\partial\left(\frac{g}{y}\right)}>0\right)$. 
Igualando a (9) con cero obtenemos, adicionalmente, el tamaño del sector público que maximiza el producto per cápita a largo plazo

$$
\tau^{*}=1-\frac{\alpha}{\epsilon_{1} \frac{\partial d}{\partial(g / y)}} \quad \operatorname{con} 0 \leq \tau^{*} \leq 1
$$

En consecuencia, una menor progresividad no necesariamente aumenta la desigualdad, pero una disminución de los gastos sociales si lo hará. Esto es, en la medida en que el gasto social sea eficaz en la reducción de desigualdades, la redistribución podría aumentar el crecimiento, siempre y cuando el peso del sector público en la economía sea pequeño. Esto último evitaría que la productividad de la política de gasto redistributivo sea decreciente.

Así, por ejemplo, un sistema de pensiones públicas financiado con impuestos sobre la renta puede internalizar la externalidad provocada por una fuerza laboral con capital humano bajo -ya sea por razones de edad o instrucción-, la cual reduce el capital humano promedio y la productividad del resto de los trabajadores de una economía. Esto implica que una política fiscal que utilice al gasto público en transferencias de pensiones como instrumento, podría corregir los efectos negativos que generan los trabajadores con capital humano reducido. Sin embargo, si los aumentos del gasto parten de niveles elevados reducirán el dinamismo económico provocado por la distorsión de los impuestos recaudados.

\section{La experiencia del desarrollo y el papel de la política fiscal: el caso de la economía mexicana}

El comportamiento económico de las últimas décadas ha sido estable en los países desarrollados, e inestable y con tendencia a la baja en su crecimiento en la mayor parte de los países emergentes, exceptuando los casos de los denominados BRIC (Brasil, Rusia, India y China). En el caso de la economía mexicana, ésta ha tenido como característica el empeoramiento de su desempeño, manifestado en dos rasgos principales: 
José L. HERnÁNDEZ

i) Crecimiento económico: el PIB promedio de los últimos 30 años es de $2.56 \%{ }^{11}$ y de $2.37 \%{ }^{12}$ en la producción industrial.

ii) Competitividad: a partir del año 2000 la penetración de las exportaciones en el mercado de EU ha venido disminuyendo, mientras que China, por ejemplo, la ha incrementado a nivel global.

En este sentido, puede decirse que hasta antes de la crisis de 1994, los determinantes del comportamiento económico de la economía mexicana han estado vinculados a las caídas abruptas en el precio del petróleo, mismas que han ocasionado crisis fiscales, corridas masivas de flujos de capital, devaluaciones graves y elevadas tasas de inflación, con la consecuente caída de los términos de intercambio y el deterioro de la balanza de pagos. En cambio, la crisis de 1994 tiene que ver con el manejo no óptimo del financiamiento externo que, sumado con la inestabilidad política y el uso indiscriminado de los instrumentos financieros para financiar el consumo personal, dio como resultado un deterioro significativo de la balanza de pagos que culminó en la adopción del régimen de libre flotación tras una fuerte devaluación del tipo de cambio. Es así que, la combinación de choques exógenos que afectan la productividad del país y los errores de política económica son las causas reconocidas de las crisis económicas presentadas hasta 1994.

Una vez identificadas las principales causas de las crisis en México, es importante señalar que dichos efectos generaron una dinámica de represión de la capacidad productiva del país, en donde la función del gobierno en la economía mexicana pasó de promotor del crecimiento económico, por medio de la inversión pública, a benefactor de procesos de liberalización económica implicando un cambio estructural en el diseño macroeconómico de las variables de política económica, ${ }^{13}$ sobre todo por la cuestión de obtener recursos fiscales

11 Si omitimos los años de 1980 y 1981 del periodo considerado, años en los cuales el PIB creció a tasas de $8.3 \%$ y $8.5 \%$, respectivamente, la tasa de crecimiento promedio anual fue de $2.10 \%$ para el periodo 1982-2009, siendo los años de 1996 a 2000 el periodo que registra el mejor comportamiento económico, con una tasa anual de crecimiento promedio de 5.5\%. Por consecuencia, el periodo de 1990 a 1999 es el que ha presentado una mayor tasa de crecimiento promedio anual de la economía (3.4\%), en contraste con la última década (2000-2009) que reportó la tasa de crecimiento promedio anual más baja (2.0\%).

12 El mayor incremento de la producción industrial ocurre en la década de los noventa, donde el crecimiento promedio anual fue de $4.19 \%$, a pesar de la disminución de $7.81 \%$ ocurrida en 1995, lo cual se explica por el dinamismo del sector exportador. Sin embargo, para el periodo que comprende de 2000 a 2009 la tasa de crecimiento promedio anual fue de $0.68 \%$, pues durante los años de 2001 a 2003 y de 2008 a 2009 se registraron caídas de 3.48, 0.09, 2.43, 0.52 y 6.91\% en este indicador.

13 Considérese por ejemplo que la inversión física pública como proporción del PIB decreció de un promedio anual de 5.42\% en el periodo 1980-1989 a 2.88\% en 1990-1999, y continuó en descenso hasta 
para cumplir con los compromisos de la deuda externa por medio de los ajustes en el gasto público, lo que implicó dejar de promover la demanda y capacidad productiva interna, dando como resultado una disminución de los ritmos de crecimiento económico como se muestra en el Cuadro 1.

\section{Cuadro 1}

\section{El crecimiento económico de la economía mexicana: 1960-2009}

\section{(miles de pesos)}

\begin{tabular}{|c|c|c|c|c|c|c|c|c|c|c|}
\hline CONCEPTO & $1960-1969^{1}$ & $\mid 1970-1979^{1}$ & $1980-1989^{1}$ & $1990-1999^{1}$ & $2000-2004^{1}$ & 2005 & 2006 & 2007 & 2008 & 2009 \\
\hline \multicolumn{11}{|l|}{ PRODUCTO INTERNO BRUTO } \\
\hline A PRECIOS CONSTANTES: $2005=100$ & $1,834.89$ & $3,476.83$ & $5,350.13$ & $6,799.51$ & $8,552.96$ & $9,220.7$ & $9,687.1$ & $10,012.9$ & $10,165.9$ & $9,555.3$ \\
\hline A PRECIOS DE MERCADO & 0.24 & 1.28 & 135.19 & 2,146.76 & $6,736.33$ & $9,220.7$ & $10,344.1$ & $11,290.8$ & $12,172.3$ & $11,888.1$ \\
\hline DEFLACTOR IMPLÍCITO (ÍNDICE) & 0.01 & 0.27 & 2.45 & 30.35 & 78.51 & 100.00 & 106.78 & 112.76 & 119.74 & 124.41 \\
\hline TASA DE CRECIMIENTO REAL (\%) & 7.2 & 6.5 & 2.3 & 3.4 & 2.6 & 3.3 & 5.1 & 3.4 & 1.5 & $(6.0)$ \\
\hline \multicolumn{11}{|c|}{ FORMACIÓN BRUTA DE CAPITAL FIJO } \\
\hline A PRECIOS CONSTANTES: 2005 $=100$ & 323.00 & 711.60 & $1,093.80$ & $1,295.90$ & $1,698.10$ & $1,868.3$ & $2,031.2$ & $2,122.1$ & $2,251.9$ & $2,060.0$ \\
\hline A PRECIOS DE MERCADO & 0.01 & 0.27 & 24.50 & 418.28 & $1,332.40$ & $1,868.3$ & $2,169.0$ & $2,392.9$ & $2,696.3$ & $2,562.9$ \\
\hline TASA DE CRECIMIENTO REAL (\%) & 9.1 & 7.3 & (1.9) & 4.6 & 0.9 & 5.7 & 8.0 & 4.3 & 5.8 & (9.3) \\
\hline
\end{tabular}

${ }^{1}$ Promedio anual del periodo.

Fuente: elaboración propia con base en: IMF, International Financial Statistic.

En el cuadro se muestra que la tasa de crecimiento del producto interno bruto es consistente con el crecimiento promedio de la formación bruta de capital fijo, aportado tanto por el sector privado como por el sector público, cuyas tasas de crecimiento promedio anual fueron de $9.1 \%$ y $7.3 \%$, para las décadas de los sesenta y setenta del sigloxx, respectivamente. Esta consistencia es más fuerte en las últimas dos décadas donde el coeficiente de correlación entre el producto interno bruto y la formación de capital fijo es de 0.88 , mismo que contrasta con el de las dos décadas de máximo crecimiento económico de la economía mexicana de 0.60 . Esto significa entonces que la diversificación de las fuentes de crecimiento se ha venido reduciendo en los últimos años con el proceso de reformas estructurales consolidadas en los años noventa, dando por resultado ritmos de crecimiento promedio anual de $3.4 \%$ y $2.0 \%$

llegar a 2.82 durante el periodo 2000-2009. Esto considerando que aun durante la mayor parte de la década de los ochenta, el gasto público no tuvo una contracción sino una recomposición del mismo como producto de la crisis económica de 1982, al reducirse la participación del gasto programable (gasto corriente y de capital) e incrementar la participación del gasto no programable (intereses, amortizaciones y participaciones de deuda pública), llegando el primero a representar la mitad del segundo, entonces los efectos del gasto público en la economía se constituyeron como no productivos. 
José L. HERNÁNDEZ

para el producto interno bruto y de $4.9 \%$ y $1.9 \%$ para la formación bruta de capital fijo.

En cambio, como respuesta a la crisis de la deuda de 1982 que, entre otras cosas, generó caídas en la producción de $0.6 \%$ y 3.5\% (en términos reales a precios de 2005) entre 1982 y 1983, en el periodo de 1985 a 1991 la estrategia gubernamental estuvo enfocada a llevar a cabo políticas de estabilización económica, abandonando por completo la estrategia de industrialización por sustitución de importaciones e implantando, a partir de ello, un programa de liberalización y privatización permanente. La culminación de este proceso fue la apertura comercial de la economía mexicana que se consolidó con la entrada en vigor del Tratado de Libre Comercio de América del Norte (TLCAN) en 1994.

Esta estrategia produjo un retraimiento general del sector público en las actividades productivas y un cambio en las herramientas de la política fiscal para la promoción del crecimiento. Dicho cambio consistió en el trade off entre la menor utilización in extenso del gasto público en actividades económicas productivas y de formación directa de capital y un impulso a iniciativas de promoción de la formación del capital privado tales como créditos generales y específicos para la industria manufacturera exportadora, créditos fiscales de empleo y reducción de las tasas impositivas para los corporativos.

Asimismo, como parte del programa de austeridad fiscal introducido en 1986 con el fin de estabilizar la economía, las autoridades gubernamentales redujeron el gasto de capital, afectando con ello la inversión física del sector público, sobre todo en el periodo 1990-1999, pues una vez concluido el proceso de renegociación de la deuda de fines de la década de los ochenta, el gasto no programable(destinado al servicio dela deuda), disminuyó considerablemente hasta alcanzar una contracción del gasto público total de $0.60 \%$ promedio anual. Además, producto del proceso de cambio estructural ocurrido en la composición del gasto público durante la década de los ochenta, la inversión pública federal disminuyó su participación en la economía mexicana al pasar de $5.42 \%$ en el PIB en estos años a $2.88 \%$ en la década siguiente y a $2.82 \%$ en la última década. Aunque, en el año 2009 alcanzó una participación de 4.65\% con una tasa de crecimiento de $38.44 \%$.

También, cabe destacar que la participación del gasto público total en el producto interno bruto de la economía mexicana pasó de un promedio anual de $36.58 \%$, en la década de los ochenta del siglo pasado, a una participación promedio anual respecto al PIB de $21.93 \%$ en la década de los noventa, y de $22.26 \%$ en la primera década del siglo xxi, siendo financieramente insostenible 
dadas las limitaciones de los ingresos públicos obtenidos, como se muestra en el Cuadro 2 donde puede observarse que existe un desequilibrio entre los ingresos públicos obtenidos por la tributación y explotación de recursos propiedad del Estado; por lo cual, la medida recurrente por el sector público para financiar el exceso de gasto ha sido el endeudamiento público, interno y externo, el cual es un instrumento convencionalmente utilizado para evitar las presiones fiscales necesarias y financiar los déficits provocados por los excesos de los gastos respecto a los ingresos públicos.

Aunque puede destacarse que el financiamiento público impositivo directo se ha mantenido en promedio durante los últimos 20 años en alrededor de $50 \%$ del total de los ingresos tributarios, es innegable su tendencia creciente donde pasó de constituir el $41.5 \%$ en 1990 al 53.92\% en 2010, alcanzando su punto máximo en 2008 con el $62.9 \%$ del total de los ingresos tributarios recaudados. Mientras tanto, los ingresos tributarios indirectos promedian el $46 \%$ del total de ingresos tributarios con una tendencia descendente en su participación respectiva durante el periodo considerado (estos impuestos descendieron del 56\% en 1990 a 43\% en 2010). Como ejemplo inequívoco de esta tendencia destaca el IVA, principal impuesto al consumo que ha venido creciendo en el periodo considerado, pasando del $34 \%$ del total de los ingresos tributarios en 1990 al 40\% en 2010.

A partir de lo anterior, puede afirmarse que la evolución y estructura de la composición de los ingresos públicos, refiera que la carga fiscal de los gastos públicos en México no recae directamente sobre el ingreso de los contribuyentes, sino que éstos vienen sufriendo de un ilusionismo fiscal provocado por la irresponsabilidad fiscal en materia de gasto público. Sin embargo, contrario a lo esperado, con la implantación de las nuevas herramientas de política fiscal, la participación de la inversión del sector privado en la formación bruta de capital, ha ido decreciendo durante el periodo analizado. De tener una participación de $25.73 \%$ respecto al PIB en 1980, la formación bruta de capital fijo descendió a un promedio anual de $19.62 \%$ en la década de los ochenta, $17.85 \%$ en la década de los noventas del siglo pasado hasta llegar a 20.09\% en el periodo 2000-2009. Esto ha sido congruente con la disminución de la inversión extranjera directa, en tanto las necesidades de financiamiento de la inversión privada para la formación bruta de capital fijo ha disminuido, por lo cual el ahorro externo se ha redirigido a la inversión de cartera. Ello explica el dinamismo decreciente del mercado interno que ha propiciado el bajo ritmo de crecimiento de la economía mexicana y que constituye el objetivo central de los últimos años. (cfr. Hernández, 2010: Cuadro 5). 
José L. HeRnÁNDEZ

\section{Cuadro 2}

\section{Estructura fiscal de México: 1990-2010 (millones de pesos)}

\begin{tabular}{|c|c|c|c|c|c|c|c|c|c|}
\hline \multirow{2}{*}{ CONCEPTO } & \multicolumn{9}{|c|}{ AÑOS } \\
\hline & 1990 & 1995 & 2000 & 2005 & 2006 & 2007 & 2008 & 2009 & 2010 \\
\hline INGRESOS TOTALES & $187,701.6$ & $418,375.4$ & 1,178,813.2 & $\mid 1,947,816.2$ & $2,263,602.6$ & $2,485,785.1$ & $2,860,926.4$ & $2,817,185.4$ & $2,960,268.2$ \\
\hline GOBIERNO FEDERAL & $118,665.3$ & $280,144.4$ & $868,267.7$ & $1,412,504.9$ & $1,558,808.1$ & $1,711,220.6$ & $2,049,936.3$ & $2,000,448.0$ & $2,080,064.3$ \\
\hline TRIBUTARIOS & $79,317.3$ & $170,305.6$ & $581,703.4$ & $810,510.9$ & $890,078.2$ & $1,002,670.1$ & $994,552.3$ & $1,129,552.5$ & $1,260,458.7$ \\
\hline DIRECTOS & $32,972.1$ & $73,705.4$ & $258,754.2$ & 384,5218 & $448,099.8$ & $527,183.6$ & $626,508.6$ & $594,796.2$ & $679,739.2$ \\
\hline ISR & $32,972.1$ & $73,705.4$ & $258,754.2$ & 384,5218 & $448,099.8$ & $527,183.6$ & $562,222.3$ & $534,190.6$ & $626,546.1$ \\
\hline IETU & 0.0 & 0.0 & 0.0 & 0.0 & 0.0 & 0.0 & $46,586.0$ & $44,717.9$ & $45,067.2$ \\
\hline IDE & 0.0 & 0.0 & 0.0 & 0.0 & 0.0 & 0.0 & $17,700.3$ & $15,887.7$ & $8,125.9$ \\
\hline INDIRECTOS & $44,219.6$ & $87,640.0$ & $304,011.5$ & $397,197.5$ & $408,670.3$ & $438,147.1$ & $329,147.0$ & $489,479.5$ & $535,697.7$ \\
\hline IVA & $26,635.6$ & $51,785.1$ & $189,606.0$ & $318,432.0$ & $380,576.1$ & $409,012.5$ & $457,248.3$ & $407,795.1$ & $504,433.6$ \\
\hline IEPS & $11,202.8$ & $24,710.0$ & $81,544.1$ & $49,627.1$ & $-5,2415$ & $-6,7918$ & $\cdot 168,325.2$ & $50,567.4$ & $4,452.7$ \\
\hline IMPORTACIÓN & 6,3812 & $11,144.9$ & 32,8614 & $26,820.5$ & $31,726.4$ & $32,188.0$ & $35,783.1$ & $30,196.4$ & $24,515.1$ \\
\hline RENDIMIENTOS PETROLEROS & 0.0 & 0.0 & 0.0 & $2,317.9$ & 1609.3 & $3,738.4$ & $4,440.8$ & 920.6 & $2,296.3$ \\
\hline OTROS & $2,125.6$ & $8,960.2$ & $18,937.7$ & $28,791.6$ & $33,308.1$ & $37,339.4$ & $38,896.7$ & $45,276.8$ & 45,0218 \\
\hline NO TRIBUTARIOS & $39,348.0$ & $109,838.8$ & $286,564.3$ & $601,994.0$ & $668,729.9$ & $708,550.5$ & $1,055,384.0$ & $870,895.5$ & $819,605.6$ \\
\hline ORG. DE CONTROL DIRECTO & $69,036.3$ & $138,231.0$ & $310,545.5$ & $535,311.3$ & $704,794.5$ & $774,564.5$ & $810,990.1$ & $816,737.4$ & $880,203.9$ \\
\hline PEMEX & 56,5917 & $138,905.1$ & $385,498.2$ & $726,536.6$ & $861,279.2$ & $880,698.1$ & $1,054,626.1$ & $874,163.9$ & $972,973.2$ \\
\hline GASTOS TOTALES & $204,215.4$ & $421,549.8$ & $1,239,266.4$ & $1,958,012.2$ & $2,255,221.4$ & $2,482,503.5$ & $2,872,608.3$ & $3,088,876.7$ & $3,333,552.7$ \\
\hline GASTO PROGRAMABLE & $112,676.3$ & $282,107.5$ & $852,029.3$ & $1,458,540.1$ & $1,656,938.1$ & $1,894,952.9$ & $2,210,196.9$ & $2,436,548.8$ & $2,618,500.1$ \\
\hline GASTO CORRIENTE & $85,293.2$ & $223,085.2$ & $705,484.9$ & $1,185,625.0$ & $1,338,428.5$ & $1,489,975.8$ & $1,678,213.8$ & $1,829,908.8$ & $1,972,392.3$ \\
\hline SERVICIOS PERSONALES & 33,1018 & $116,924.7$ & $392,052.2$ & $557,421.9$ & 610,6515 & $653,559.9$ & $709,820.4$ & $765,430.8$ & $799,945.1$ \\
\hline OTROS GASTOS DE OPERACIÓN & $42,228.1$ & $83,269.5$ & $217,012.9$ & $411,162.9$ & $487,153.2$ & $576,250.0$ & $638,395.8$ & 694,6413 & $758,255.6$ \\
\hline AYUDAS, SUBSIDIOS Y TRANSFERENCIAS & $9,963.3$ & 22,8910 & $96,419.8$ & $217,040.2$ & $240,623.8$ & $260,165.9$ & $329,997.6$ & $369,836.7$ & 414,1916 \\
\hline GASTO DE CAPITAL & $27,383.1$ & $59,022.3$ & $146,544.4$ & $272,915.1$ & $318,509.6$ & 404,977.1 & $531,983.1$ & $606,640.0$ & $646,107.8$ \\
\hline INVERSIÓN FISICA & $22,843.1$ & 518910 & $139,356.2$ & $220,110.6$ & $256,308.6$ & $317,157.9$ & 373,9611 & $549,325.0$ & $608,625.4$ \\
\hline INVERSÓN DIRECTA & 19,525.4 & $40,378.4$ & 77,1412 & $87,794.2$ & $96,594.6$ & $155,494.4$ & $165,972.9$ & $361,630.4$ & $419,079.3$ \\
\hline TRANSFERENCIAS PARA INVERSIÓN & $3,317.7$ & $11,512.6$ & $62,215.0$ & $132,316.4$ & $159,714.0$ & $161,663.5$ & $207,988.2$ & $187,694.6$ & $189,546.1$ \\
\hline INVERSIÓN FINANCIERA & $4,540.0$ & 7,1313 & $7,188.2$ & $52,804.5$ & 62,2010 & $87,819.2$ & $158,022.0$ & $57,315.0$ & $37,482.4$ \\
\hline GASTO NO PROGRAMABLE & $91,539.1$ & $139,442.3$ & $387,237.1$ & $499,472.1$ & $598,283.3$ & $587,550.6$ & $662,411.4$ & $652,327.9$ & $715,052.6$ \\
\hline COSTO FINANCIERO & $67,118.0$ & $69,769.0$ & $140,499.5$ & $182,731.3$ & $211,465.0$ & $210,943.0$ & $197,070.0$ & $231,736.0$ & $242,039.8$ \\
\hline INTERESES Y COMISIONES GOB. FED. & $59,916.7$ & $55,276.6$ & $115,943.4$ & $144,988.7$ & $153,835.1$ & $160,658.4$ & $170,079.1$ & $200,189.0$ & $202,549.9$ \\
\hline INTERESES Y COMISIONES ORG. Y EMP. & 7,2013 & $14,492.4$ & $24,556.1$ & $37,742.6$ & $57,629.9$ & $50,284.6$ & $26,990.9$ & 31547.0 & $39,489.9$ \\
\hline PROGRAMA DE APOYO A DEUDORES & 0.0 & $15,000.0$ & $60,517.6$ & $27,455.1$ & $38,600.1$ & $28,013.0$ & $30,042.6$ & $31,076.4$ & $13,720.8$ \\
\hline PARTICIPACIONES & $20,717.4$ & $49,158.9$ & $178,136.2$ & $278,892.4$ & $329,337.3$ & $332,757.7$ & $423,454.9$ & $375,717.3$ & $437,334.5$ \\
\hline ADEFAS & $3,703.7$ & $5,514.4$ & $8,083.8$ & $10,393.3$ & $18,880.9$ & $15,836.9$ & $11,843.9$ & $13,798.2$ & $21,957.5$ \\
\hline BALANCE PRESUPUESTARIO & $-16,513.8$ & $-3,174.4$ & $-60,453.2$ & $-10,196.0$ & $8,381.2$ & $3,281.6$ & $-11,681.9$ & $-271,691.3$ & $-373,284.5$ \\
\hline BALANCE FINANCIERO & .2752 .4 & 2973.7 & $\cdot 143.5$ & 70.6 & 1552.4 & 1528.4 & 3736.5 & $\cdot 1794.7$ & 2704.7 \\
\hline BALANCE PÚBLICO & $-19,266.2$ & -200.7 & $-60,596.7$ & $-10,125.4$ & $9,933.6$ & $4,810.0$ & $-7,945.4$ & $-273,486.0$ & $-370,579.8$ \\
\hline FINANCIAMIENTO & $19,266.2$ & 200.7 & $60,596.6$ & $10,125.2$ & $-9,933.8$ & $-4,809.9$ & $7,945.6$ & $273,486.0$ & $370,579.8$ \\
\hline EXTERNO & .730 .3 & $99,820.8$ & $.57,748.7$ & $-49,857.5$ & $-241,880.2$ & $\cdot 188,2616$ & $-83,279.4$ & $44,725.0$ & $170,438.5$ \\
\hline INTERNO & $19,996.5$ & $99,620.1$ & $118,345.3$ & $59,982.7$ & $231,946.4$ & 183,4517 & $91,225.0$ & $228,761.0$ & $200,141.3$ \\
\hline
\end{tabular}

Fuente: SHCP, Cuenta de la Hacienda Pública Federal, años 1990-2010. 
Por otro lado, la situación de la distribución del ingreso en México es un problema estructural de desigualdad económica prevaleciente a lo largo de toda la historia económica del país, por lo tanto es inherente a las características productivas de la economía siendo un freno para su desarrollo. Esto se debe, en gran medida, a la permanencia de esquemas institucionales y prácticas económicas y sociales que dificultan la distribución equitativa entre los integrantes de la sociedad mexicana con respecto al acceso a servicios de alimentación, vivienda, educación, salud, laborales y financieros, entre otros.

Además, si consideramos que tanto los constantes ciclos recesivos de la economía, ocurridos en los últimos 30 años, como la incorporación acelerada a una economía global han impedido mantener un ritmo de crecimiento sostenido y han contribuido a ampliar la brecha existente entre los individuos en materia de ingreso. En este sentido, la Comisión Económica Para América Latina de la Organización de las Naciones Unidas (CEPAL) encuentra que el estancamiento en materia de distribución del ingreso en América Latina y el Caribe, ha ocasionado que en los últimos 20 años los grados de concentración de la riqueza sean los más elevados del mundo. ${ }^{14}$

Para tener una idea de la magnitud de la desigualdad en la distribución del ingreso en México, de acuerdo con la Encuesta Nacional de IngresoGasto de los Hogares (ENIGH) para el año 2000, el 10\% de la población de menores ingresos concentró entre $0.70-2.60 \%$ del ingreso, mientras que el $10 \%$ con mayores ingresos concentró entre 44-53\%. Considerando sólo el ordenamiento por ingreso total en deciles de familias, una persona promedio ubicada en el décimo decil de ingreso percibía un ingreso 70 veces mayor al que recibía en promedio una persona ubicada en el primer decil de ingreso. Si se considera el tamaño de las familias y el bienestar de los individuos mediante el ingreso per cápita, se encuentra que una persona que corresponde al $10 \%$ de la población con mayores ingresos tiene un ingreso per cápita que equivale a 47 veces el ingreso per cápita de una persona del $10 \%$ de la población de menores ingresos.

14 Esto puede ser resultado del esquema de competencia implementado por el Estado que, con el afán de desarrollar el mercado, contribuyó al establecimiento estructural de la concentración del ingreso. En este sentido, la CEPAL, en su informe sobre el Panorama Social de América Latina 2001, señala como factores explicativos del comportamiento de la distribución del ingreso la trayectoria del empleo y los ingresos laborales. En este sentido, individuos con mejores condiciones de alimentación, salud, educación (y todos los aspectos culturales, psicológicos y sociales que se derivan de la presencia o ausencia de lo anterior), tienen una probabilidad mayor, respecto al resto, de acceder a un empleo mejor remunerado. 
La situación presenta una mejoría en los primeros deciles si se le agrega al ingreso permanente de los hogares todas aquellas transferencias producto de los programas sociales, como son el subsidio eléctrico, educativo, Procampo, Oportunidades, adultos mayores, etc., aunque es importante señalar que la distribución de éstos programas sociales han pasado de ser ligeramente progresivos hasta 2006 a ser regresivos en 2008 para los deciles IV-V conforme los datos del Cuadro 3.

Una explicación posible sobre la ineficacia de los programas sociales puede deducirse a partir dela hipótesis de que dichos programas han sido capturados por grupos de interés, producto de la definición laxa de los objetivos de los programas. Esto ha provocado que la incidencia en la distribución del ingreso sea regresiva en términos generales, pues quienes mayores aportes realizan a su financiamiento (deciles IV a VIII), en términos de la proporción de su ingreso percibido, reciben menos beneficios. Lo anterior a pesar de que, conforme los Informes de la Cuenta Pública Federal emitidos por la Secretaría de Hacienda y Crédito Público (SHCP), la evolución del gasto social creció $43.3 \%$ en términos reales entre 2002 y 2008, donde los rubros de mayor crecimiento fueron los del subsidio eléctrico en tarifas residenciales, el gasto en pensiones y transferencias directas (Oportunidades).

En consecuencia, para conocer los efectos de los instrumentos de la política fiscal (impuestos y gastos) sobre la distribución del ingreso, es necesario analizar la incidencia de éstos sobre la distribución por deciles de ingresos y gastos de la población. La medida utilizada para ello es el coeficiente de Gini, ${ }^{15}$ y conforme los cálculos de la SHCP, este coeficiente pasó de 0.45 en el año 2000 a 0.465 en 2008, con lo que se confirma que los programas sociales no han tenido una incidencia redistributiva fuerte. Asimismo, la distribución del gasto de los hogares muestra que, excepto en el último decil, la incidencia del ahorro per cápita es muy baja o nula, por lo cual esta situación incide completamente sobre la disponibilidad de fondos que tiene la economía mexicana y las necesidades de gasto que tiene la población, lo que contribuye

15 El índice o coeficiente de Gini, formulado por el economista italiano Conrado Gini, es la medida más usada para medir la desigualdad en la distribución del ingreso pues cumple con cuatro propiedades básicas: a) satisface el principio de transferencia, también conocido como condición Pigou-Dalton (si se presenta una transferencia regresiva de ingreso, el índice aumenta); $b$ ) independencia de la escala de ingreso (establece que el valor del índice no depende de la unidad monetaria); c) satisface el principio de población (el cual establece que el índice debe ser independiente del tamaño de la población analizada) y, d) posibilidad de descomposición del índice; sus límites (0 y 1) permiten una fácil explicación del grado de desigualdad: valores cercanos a 0 indican baja desigualdad; y valores cercanos a 1 muestran alta desigualdad. 


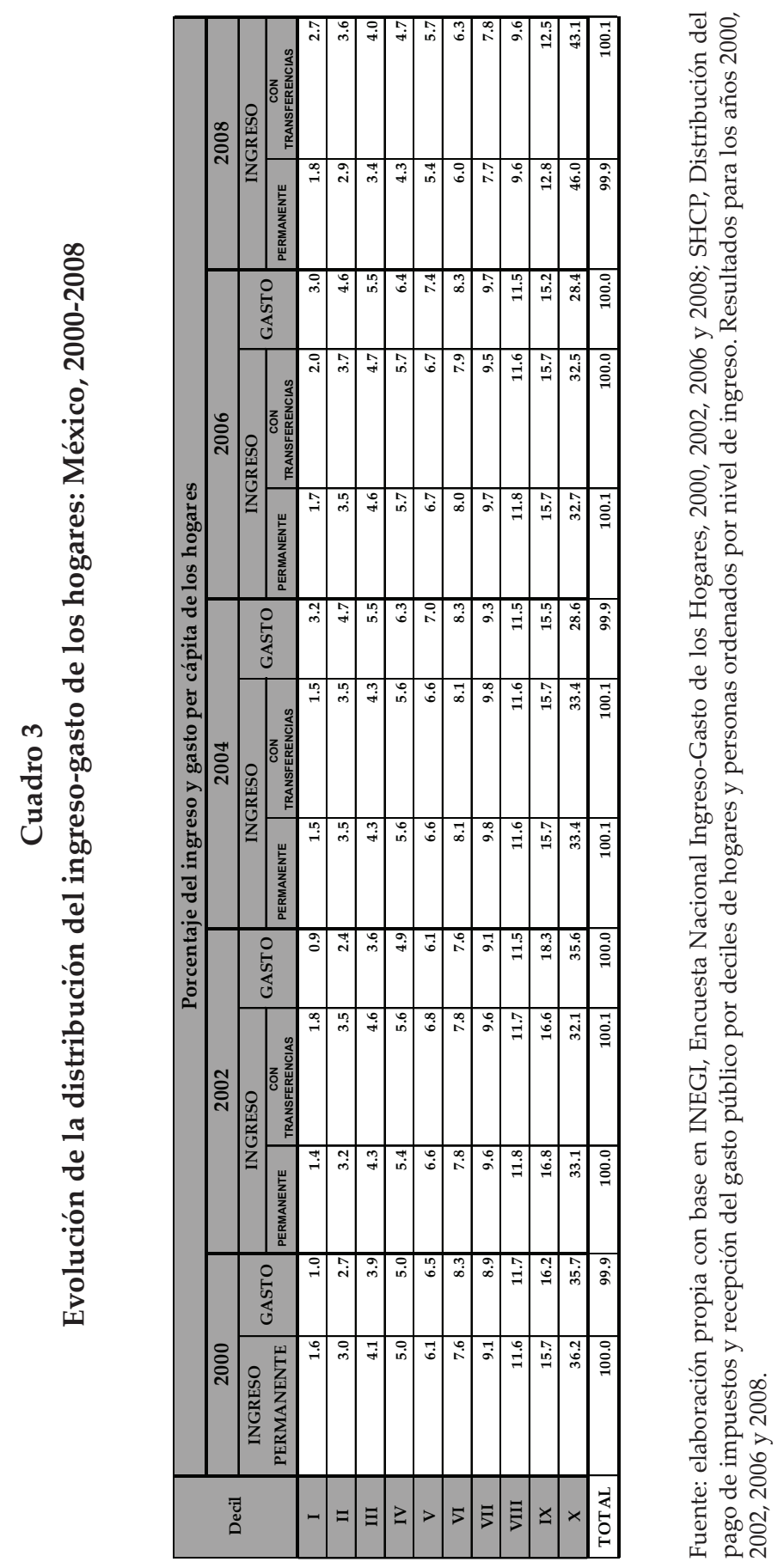


José L. HernándeZ

a mantener una insuficiencia de ahorro que sólo puede ser cubierta con la provisión pública productiva.

\section{Conclusiones}

La principal hipótesis de este trabajo es que la política fiscal, basada en la implementación de una política de gasto público productivo con impuestos compensadores, puede provocar economías a escala, teniendo efectos positivos sobre el crecimiento económico y la distribución del ingreso. ${ }^{16} \mathrm{No}$ obstante, cabe mencionar que, conforme los resultados teóricos del modelo desarrollado en la segunda sección, aunque una menor progresividad de los impuestos no necesariamente aumenta la desigualdad, una disminución de los gastos sociales sí lo hará. Esto es, en la medida en que el gasto social sea eficaz en la reducción de desigualdades, la redistribución podría aumentar el crecimiento, siempre y cuando el peso del sector público en la economía sea pequeño. Esto último evitaría que la productividad de la política de gasto redistributivo sea decreciente ${ }^{17}$ y que se considere que el gasto social tiene

16 Es importante mencionar que una restricción estructural para una economía en crecimiento es la desigualdad en la distribución del ingreso puesto que ésta afecta directamente a la eficiencia productiva del capital humano, en el sentido de que una mayor desigualdad provoca una ineficiencia productiva debido a la diferencia de ingresos que imposibilita el desarrollo pleno de la capacidad productiva de los estratos más bajos de ingresos dentro de una economía. Por tanto, el gasto público productivo, una vez separado de éste la inversión pública, representa el gasto social o en transferencias. Si el sector público decidiera incrementar permanentemente los impuestos para destinar los recursos recaudados a este tipo de gasto, entonces tendríamos que en el largo plazo, en una economía donde el capital no sea tan productivo como pudiera serlo, la política redistributiva podría ser beneficiosa para el crecimiento. La condición es que el gasto social ejercido sea eficaz en su objetivo redistributivo, pues el incremento del coeficiente de la igualdad del ingreso hace a los factores más productivos al incrementar sus capacidades permanentemente.

17 En este sentido, implementar un programa de capacitación y adiestramiento laboral financiado con impuestos sobre la renta, puede internalizar la externalidad provocada por una fuerza laboral con capital humano bajo -ya sea por razones de edad o instrucción- la cual reduce el capital humano promedio y la productividad del resto de los trabajadores de una economía. El gasto público en este programa podría corregir los efectos negativos que generan los trabajadores con capital humano reducido. Sin embargo, si los aumentos del gasto parten de niveles elevados, provocados por programas anteriores $\mathrm{u}$ otros que han mostrado ser ineficaces pero que se han mantenido, reducirán el dinamismo, conjuntamente con la distorsión provocada por los impuestos recaudados. La evidencia empírica para la economía mexicana, de acuerdo con el Cuadro 3, muestra que la efectividad redistributiva del gasto social en México ha sido regresiva y el mejoramiento de los primeros deciles de ingreso es producto sólo de las transferencias más no del mejoramiento de las capacidades productivas, pues el nivel depende de la permanencia o no de las transferencias efectuadas. Ésta es la razón por la cual la productividad del gasto social es decreciente en México. 
efectos en la distribución del ingreso y éste sobre el crecimiento económico cuando dicho gasto es efectivo en la redistribución del ingreso.

Asimismo, conforme al planteamiento teórico desarrollado en la sección 2, los datos para la economía mexicana nos permiten mostrar que ni la inversión pública ni el gasto social son los determinantes para el crecimiento económico a largo plazo y, por el contrario, en el caso del gasto social, actúa en sentido contrario a éste, por lo cual su eficiencia redistributiva es regresiva debido a que no se utilizan para incrementar la capacidad productiva de los factores. Sin embargo, esto no es más que un reflejo de deficiencias estructurales en el aparato productivo de la economía mexicana durante los últimos treinta años, provocado por la inefectividad del gasto de inversión, tanto público como privado, ${ }^{18}$ y de la política social asistencialista llevada a cabo. Por consiguiente, la política gubernamental ha de ser redefinida en su función de asignar los recursos disponibles manifestados en su política de gasto público.

Esto ha generado una dinámica de represión de la capacidad productiva del país, en donde la función del gobierno en la economía mexicana pasó de ser promotor del crecimiento económico, por medio de la inversión pública, a ser benefactor de procesos de liberalización económica, reflejándose así un cambio estructural en el diseño macroeconómico de las variables de política económica, sobre todo por el hecho de obtener recursos fiscales para cumplir con los compromisos de la deuda externa por medio de los ajustes del gasto público, con el consiguiente costo de dejar de promover la demanda y capacidad productiva interna y, por lo tanto, de promover el crecimiento económico a ritmos de $7 \%$ promedio anual de finales de los años setenta y principios de los ochenta del siglo pasado. En este sentido, puede pensarse que un elemento que pudo haber contribuido a la reducción del ritmo de crecimiento de la economía mexicana durante los pasados 25 años ha sido la recomposición del gasto público utilizado en actividades no productivas.

18 La inefectividad estructural de la inversión privada y pública radica, por un lado, en el freno de la capacidad instalada por el decrecimiento de inversiones netas debido a la capacidad limitada de talento, experiencia y espíritu empresarial y aversión al riesgo natural de los inversionistas privados, por el cambio sobre la función del sector público en la economía iniciada en la década de los ochenta, y por el estancamiento e inestabilidad económica provocada por los manejos erróneos de la política económica. Estos factores han limitado la capacidad para absorber los beneficios del gasto público productivo en la generación de crecimiento económico y ampliación de la capacidad productiva de la economía mexicana en los pasados treinta años. 
José L. HERNÁNDEZ

Asimismo, el análisis de la estructura fiscal en México muestra, además, que ha existido una composición regresiva en materia productiva respecto al gasto público debido a que, a pesar del mayor endeudamiento del sector público, el financiamiento de la carga del costo financiero ha mermado la oferta de servicios que bien podrían mejorar la productividad de los factores y generar mayores ingresos tributarios en medida suficiente como para financiar los futuros reembolsos e intereses de la deuda. Además, si a lo anterior agregamos que se han canalizado recursos a la provisión de servicios sin impacto productivo, con el objetivo implícito de tan sólo mantener el nivel de empleo público (gasto corriente), entonces se puede afirmar que si son los servicios los que contribuyen a mejorar la productividad de los factores, el decremento en la oferta de servicios con impacto productivo representa el origen de la debilidad estructural que impide el impulso económico para la consecución del desarrollo.

\section{Referencias bibliográficas}

Albala-Bertrand, J. M. y E. C. Mamatzakis (2001), "Is Public Infraestructure Productive? Evidence from Chile", Applied Economic Letters, vol. 8, pp. 195-9. Baldacci, E., B. Clements y S. Gupta (2003), “Utilizar la política fiscal para estimular el crecimiento", Finanzas y Desarrollo, Diciembre, pp. 28-31.

Barro, R. J. (1990), “Government Spending in a Simple Model of Endogenous Growth", The Journal of Political Economy, vol. 98, núm. 5, Parte 2, The Problem of Development: A Conference of Institute for the Study of Free Enterprise Systems, Octubre, pp. S103-S125.

Bergstrom, T. C., R. P. Goodman, L. Blume y H. Varian (1986), “On the Private Provision of Public Goods", Journal of Public Economics, vol. 29, núm. 1, Febrero, pp. 25-49.

Conrad, K. y H. Seitz (1994), "The Economic Benefits of Public Infrastructure", Applied Economics, vol. 26, núm. 4, pp. 303-311.

Doménech, R. y J. R. García (2002), “Optimal Taxation and Public Expenditure in a Model of Endogenous Growth", Topics in Macroeconomics, vol. 2, núm. 1, pp. 1-26.

Easterly, W. y S. Rebelo (1993), “Fiscal Policy and Economic Growth”, Journal of Monetary Economics, vol. 32, pp. 417-58.

Feltenstein, A. y H. Jiming (1999), "An Analysis of the Optimal Provision of Public Infraestructure: A Computational Model Using Mexican Data", Journal of Development Economics, vol. 58, núm. 1, Febrero, pp. 219-230. 
Política Fiscal, CRECIMIENTO SOSTENIDO Y DESARROLlo ECONÓMICO: LA EXPERIENCIA MEXICANA

Fisher, W. H. y S. J. Turnovsky (1998), “Public Investment, Congestion, and Private Capital Accumulation", The Economic Journal, vol. 108, núm. 447, Marzo, pp. 399-413.

Fonseca, F. de J. (2009), “El impacto de las inversiones públicas sobre la inversión privada en México, 1925-2006", Finanzas Públicas, vol. 1, núm. 1, Primer Semestre, pp. 49-78.

García-Peñalosa, C. (2003), "Distribution and Policy in the New Growth Literature" en Neri Salvadori (ed.), Old and New Growth Theories: An Assessment, Edgar Elgar, Cheltenham, U.K., pp. 215-39.

Gramlich, E. M. (1994), “Infrastructure Investment: A Review Essay”, Journal of Economic Literature, vol. 32, núm. 3, Septiembre, pp. 1176-96.

Hernández, J. L. (2009), “La composición del gasto público y el crecimiento económico", Análisis Económico, Primer Cuatrimestre, vol. 24, núm. 55, pp. 77-102.

- (2010), “Inversión pública y crecimiento económico: hacia una nueva perspectiva de la función del gobierno", Economía Teoría y Práctica, núm. 33, Segundo Semestre, pp.

- (2011), Gasto público y crecimiento económico: un análisis teórico sobre las relaciones estructurales en la generación de riqueza, Tesis doctoral, UAM. Jones, L., R. Manuelli y P. Rossi (1993), “Optimal Taxation in Models of Endogenous Growth", Journal of Political Economy, vol. 101, pp. 485-517.

Kneller, R., M. F. Bleaney y N. Gemmell (1999), “Fiscal Policy and Growth: Evidence from OECD Countries", Journal of Public Economics, vol. 74, pp. 171-90.

Kormendi, C. y G. Meguire (1985), "Macroeconomic Determinants of Growth", Journal of Monetary Economics, vol. 16, núm. 2, pp. 141-163.

Lucas, R. (1990), "Supply-side Economics: An Analytical Review”, Oxford Economic Papers, vol. 42, núm. 2, 293-317.

Musgrave, R. A. y P. Musgrave (1992), Hacienda pública teórica y aplicada, McGraw-Hill, México.

Nurske, R. (1953), Problems of Capital Formation in Under-Developed Countries, Oxford University Press.

Ramírez, M. D. (2007), "A Panel Unit Root and Panel Cointegration Test of Complementary Hypothesis in the Mexican Case: 1960-2001", Atlantic Economic Journal, vol. 33, núm. 3, Septiembre, pp. 343-56.

Rosenstein-Rodan, P. N. (1943), "Problems of Industrialization of Eastern and South-Eastern Europe", The Economic Journal, vol. 53, nos. 210-211, Junio-Septiembre, pp. 202-211. 
José L. HeRnÁNDEZ

Samuelson, P. A. (1954), "The Pure Theory of Public Expenditure", The Review of Economics and Statics, Reproducido en español en Arrow, Kenneth J. y Tibor Scitovsky (selección) (1974).

Solow, R. M. (1956), "A Contribution to the Theory of Economic Growth", The Quarterly Journal of Economics, vol. 70, núm. 1, Febrero, pp. 65-94. Turnovsky, S. (2000), "Fiscal Policy, Elastic Labor Supply, and Endogenous Growth", Journal of Monetary Economics, vol. 45, pp. 185-210. 